\title{
A QUESTÃO DA ALTERIDADE E A RESTAURAÇÃO PORTUGUESA NA OBRA DO PADRE ANTONIO VIEIRA
}

\author{
Leandro Henrique Magalhães ${ }^{l}$ \\ Faculdade do Norte Pioneiro - FANORPI \\ Centro Universitário Filadéfia - UNIFIL
}

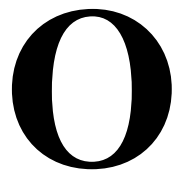

Padre Antonio Vieira é ainda hoje considerado um dos grandes escritores da língua portuguesa. Personagem marcante da história de Portugal, colecionou admiradores e inimigos mesmo após a sua morte. Falar de Vieira sem considerar esse fato é ignorar sua importância política e suas posturas controversas, como a defesa da venda de Pernambuco para os Países Baixos ou a proposta de criação de uma companhia de comércio com financiamento judeu. ${ }^{2}$

No Brasil, Antonio Vieira destacou-se pelo seu trabalho junto aos índios Tupinambá, atuando como missionário no Maranhão, no período de 1651 a 1661. Sua atuação missionária deve ser pensada a partir de suas perspectivas em relação ao futuro de Portugal que, após a restauração portuguesa, tinha por objetivo manter sua soberania e evitar o avanço castelhano sobre territórios lusitanos. Tais preocupações estariam presentes no trato de Vieira com os nativos, pois entendia as possessões americanas como parte

\footnotetext{
${ }^{1}$ Mestre em História pela Universidade Federal do Paraná - UFPR. Aluno do Curso de Doutorado pela mesma instituição. Professor da Faculdade do Norte Pioneiro - FANORPI e do Centro Universitário Filadéfia - UNIFIL. Autor do livro Olhares sobre a colônia: Vieira e os Índios, publicado pela editora da Universidade Estadual de Londrina - UEL.

${ }^{2}$ Sobre o tema, ver: FERREIRA REIS, 1993; FREITAS, 1951; CABRAL DE MELLO, 1998; MAGALHÃES, 1999b.
} 
integrante do reino e seus habitantes como súditos do rei. ${ }^{3}$ Sua postura missionária, no entanto, fora alvo de interrogações e criticas, possibilitando as mais variadas interpretações por parte dos estudiosos do jesuíta. Apresentaremos aqui, brevemente, o modo como alguns dos mais destacados estudiosos brasileiros entenderam a atuação do Padre Antonio Vieira frente à evangelização indígena.

João Francisco Lisboa, ${ }^{4}$ jornalista maranhense de princípios do Império, identifica-o como inimigo da nação e desconhecedor das necessidades dos colonos, além de classificá-lo como teimoso e ambicioso. De acordo com o autor, sua atuação junto aos nativos seria resultado de suas ambições temporais e políticas, por meio dos quais parecia buscar a garantia do poder frente às missões e aumentar sua fama junto à coroa portuguesa. Por ser conhecedor da obra de Vieira, formularia um ataque generalizado ao jesuíta, considerando-o como anti-patriota por colocar-se ao lado dos índios, ao invés de posicionar-se a favor do povo brasileiro. ${ }^{5}$ Esta biografia fora redigida em um momento de afirmação nacional, onde o patriotismo extremado poderia levar a entender-se como inimigos da nação todos aqueles que tivessem uma posição favorável à coroa. ${ }^{6}$

${ }^{3}$ Segundo João Paulo Costa, esta era uma postura comum entre os diplomatas de Portugal do período, que pensavam o reino em sua totalidade (COSTA, 1989.).

${ }^{4}$ LISBOA, 1964.

5 Para João Francisco Lisboa, os colonos portugueses seriam o verdadeiro povo brasileiro, e não os nativos.

${ }^{6}$ Existiam, no Primeiro Reinado, uma grande variedade de grupos e raças que dividiam o mesmo espaço no território. Este fato possibilitara a propagação de conflitos, onde o entre estrangeiros e brasileiros era apenas um deles. No caso específico deste tipo de conflito, devemos levar em consideração a dificuldade de se identificar o estrangeiro, sendo que, na maioria das vezes, era tido como o português. Este apresentava ainda, segundo Gladys Sabina Ribeiro, duas representações, uma que o tinha como inimigo da nação e que a qualquer momento poderia tentar recolonizar o Brasil, e outra que o via como o mais capacitado para permanecer ao lado da corte, gerando assim invejas por parte de muitos ditos brasileiros (RIBEIRO, Set.91/Ago. 92; MAGALHÃES, 1997b) 
Este seria, segundo João Francisco Lisboa, o caso de Vieira que, ao se posicionar contra a escravidão indígena, estaria representando a coroa Portuguesa, sendo identificado então como anti-patriota e defensor de Portugal. ${ }^{7}$

Já Sezinandro Luiz Menezes ${ }^{8}$ ao propor uma análise marxista da obra de Vieira, identifica-o sobretudo como explorador da mãode-obra nativa, tendo como objetivo principal o enriquecimento da Companhia de Jesus e da coroa de Portugal. Classifica como burguesas algumas de suas posturas, além de exaltar o seu espírito moderno, que se afastaria da escolástica e se aproximaria do espírito de Francis Bacon. Entende a obra de Vieira a partir de uma leitura economicista, sendo que todas suas atitudes privilegiariam tal aspecto.

Para Alfredo Bosi, ${ }^{9}$ o fundamento da obra de Vieira acerca dos indígenas brasileiros estaria nas contradições existentes entre seu discurso universalista, que objetivava a consolidação de Portugal como reino cristão, e o particularismo das ações necessárias para se alcançar tal objetivo. Os interesses coloniais seriam parte de um projeto maior, sendo muitas vezes necessário fazer concessões para garantir o sucesso. Esta perspectiva aproxima-o das interpretações dadas por

${ }^{7}$ O biógrafo fazia parte de um grupo de intelectuais que tinha como objetivo compor uma história do Brasil que possibilitasse a constituição de uma nação branca e européia, tendo no Estado seu elemento constituinte. Era este, por exemplo, o trabalho desenvolvido pelos membros do Instituto Histórica e Geográfico Brasileiro, que, segundo Lucia Maria Paschoal Guimarães: "Significou dotar o país, carente de unidade e recém-saído da condição de colônia, de um passado comum (GUIMARÃES, 1998. p.474)." O projeto político dos membros do referido Instituto era marcado pela fidelidade ao Imperador. Tal característica estaria presente também na obra de João Francisco Lisboa, que chegaria a ser enviado a Lisboa, pelo Imperador, com o objetivo de catalogar e copiar documentos considerados importantes para a História do Brasil (ODÁlIA, 1974. p.15-21).

${ }^{8}$ MENEZES, 1992.

${ }^{9}$ BOSI, 1992. 
autores portugueses como Hernani Cidade e João Lucio de Azevedo, ${ }^{10}$ que entendem a atuação missionária de Vieira a partir de suas preocupações com a restauração portuguesa, aliada a sua teoria acerca do Quinto Império. ${ }^{11}$

Também Alcir Pécora ${ }^{12}$ entende a atuação missionária de Vieira a partir de suas resoluções políticas, atentando-se, no entanto, à necessidade de inserção do índio brasileiro no corpo místico da igreja, vinculando tais idéias às suas expectativas messiânicas. A finalidade dos descobrimentos seria a conversão, o que conseqüentemente colaboraria para a expansão e solidificação da coroa Portuguesa. O índio, a partir dá, tornava-se súdito do rei de Portugal o que, teoricamente, impossibilitava a escravidão, pois a liberdade estava vinculada a sua inserção na Igreja e no reino de Portugal. O Padre Antonio Vieira atuaria a partir das necessidades da coroa, entendendo que só com seu fortalecimento e expansão seria possível garantir o sucesso da empresa missionária.

Partindo de tais reflexões, procuraremos demonstrar como Vieira elaborou seu discurso acerca do indígena brasileiro, levando em consideração tanto suas preocupações com a restauração portuguesa como suas expectativas messiânicas em relação ao reino.

\section{II}

No período de sessenta anos em que Portugal esteve sob domínio da coroa castelhana (1580-1640), a esperança de restauração de uma corte portuguesa estaria presente, intensificando-se a medida

${ }^{10}$ CIDADE, 1947; AZEVEDO, 1992.

${ }^{11}$ Baseando-se nas profecias bíblicas de Daniel acerca dos cinco impérios cristãos sucessivos, têm-se em Portugal o último destes, sendo que os anteriores foram: o assírio, o persa, o grego e o romano. Na alegoria da estátua de Nabucodonosor, Portugal seria representada pela pedra que derrubaria todos os outros elementos representados na estátua (ouro, prata, ferro e barro), tomando seus lugares (TELMO, 1977).

${ }^{12}$ PÉCORA, 1992b. 
em que o Estatuto de Tomar, ${ }^{13}$ que garantia a autonomia do reino lusitano, vinha sendo ferido, contribuindo para uma marginalização crescente da nobreza lusitana. ${ }^{14}$ Além disso, Portugal estaria sendo afetado diretamente com a política externa castelhana, seja devido à perda de territórios, seja aos freqüentes aumentos de impostos com o intuito de financiar os conflitos de Castela. ${ }^{15}$

Desse modo, tanto a política interna de centralização de poder e exclusão de parte da nobreza lusitana, como a externa, de postura bélica em relação às grandes potências européias da época, levaram ao movimento insurrecional que teria seu ápice em 01 de dezembro de 1640, protagonizada, como indicado por Pedro Cardim, não por "fidalgos inflamados por sentimentos patrióticos", ${ }^{16}$ mas por

${ }^{13}$ Após Filipe II invadir Portugal, é reconhecido rei nas Cortes de Tomar, sob o título de Filipe I. Apesar da anexação da coroa lusitana, buscou-se garantir uma distinção entre o governo castelhano e o português, o que se fez através dos capítulos das referidas cortes, denominado estatuto de Tomar. Neste se garantia que tanto os cargos de administração como o Império Ultramarino continuariam a cargo dos lusitanos e se manteriam seus regulamentos, as receitas e despesas dos dois reinos separadas e, além disso, a língua oficial do reino continuava a ser o português. Segundo Joaquim Veríssimo Serrão: "Desta forma, as cortes de 1581 fixaram o princípio da monarquia dualista: um rei com duas coroas, cada um com o seu governo próprio e conservando o pleno exercício dos direitos que lhe eram inerentes (SERRÃO, 1979. p.16)". Criava-se ainda o conselho de Portugal, para tratar exclusivamente dos assuntos referentes ao reino lusitano (MARQUES, 1995. p.289; MAGALHÃES, 1997a. p.479; ALVARES, 1993).

${ }^{14}$ A restauração portuguesa pode ser entendida como um movimento de nobres que se rebelaram contra a tendência centralizadora que comprometia os privilégios da nobreza lusitana, que vinha sendo gradualmente marginalizados pela política de Olivares. O movimento se caracterizaria assim contra o "segundo Portugal" dos Filipes, promovido a partir da ascensão de Filipe IV (III de Portugal) e, neste caso, os nobres que se mantiveram fiéis à Castela estariam fiéis ao Portugal do estatuto de Tomar. (HESPANHA, 1993).

15 SERRÃO, 1979. p.126; MARQUES, 1995. p.298.

${ }^{16}$ CARDIM, 1998. p.404. 
descontentes com a política adotada pela corte de Madri. O duque de Bragança, depois rei D. João IV, liderara o movimento, entrando em Lisboa a 06 de dezembro de 1640, sendo que no dia quinze seria realizado seu levantamento no terreiro do paço. A notícia chegaria à Madri em 07 de dezembro de 1640, sendo o movimento considerado rebelião por Filipe IV (III de Portugal), e o duque de Bragança traidor. ${ }^{17}$ A grande missão da nova monarquia seria manter e justificar a restauração portuguesa, tarefa que se apresentaria árdua, e que teria em Vieira um de seus grandes teóricos. ${ }^{18}$ Para tanto, partia-se de concepções jurídicas aliadas às proféticas, com o intuito de garantir a soberania e legitimidade da dinastia recém entronada. ${ }^{19}$

Tal questão iria permear a atuação de Vieira tanto no que se refere as suas atividades diplomáticas nas cortes da Europa como em seu trabalho missionário nas colônias portuguesas da América, onde aliaria suas preocupações em relação a consolidação da nova dinastia com a expansão do cristianismo e a confirmação de suas teorias que identificavam Portugal como Reino Universal Cristão. No Sermão da Epifania, pregado na Capela Real em 06 de janeiro de 1661, após ser expulso do Maranhão, Vieira lembraria a Rainha da necessidade de atuação junto aos nativos, pois sua conversão seria uma obrigação dos portugueses, povo eleito por Deus para este fim:

Saiba o mundo, saibam os hereges e os gentios que não se enganou Deus quando fez dos portugueses conquistadores e pregadores de seu santo nome. ${ }^{20}$

Vieira entende assim o povo português como escolhido para realizar os desígnios de Deus na terra, onde a conversão do nativo, a redução dos turcos e a conversão dos judeus seria seguida da extinção das heresias e da paz mundial, debaixo de um só pastor e

${ }^{17}$ SERRÃO, 1982. p.22.

${ }^{18}$ MAGALHÃES, 2000.

19 BUESCU, 1992.

${ }^{20}$ Sermão da Epifania, p. 20. Todos os sermões citados a partir da seguinte edição: VIEIRA, 1951. 
de um só monarca, que para ele seria o rei de Portugal, D. João IV. Para tanto, haveria de realizar as profecias a este destinadas, que seriam, segundo Vieira:

$1^{2}$ Que sairá do reino com todo o poder dele, e navegará a Jerusalém. $2^{a}$ Que desbaratará o Turco na passagem de Itália a Constantinopla. $3^{a}$ Que o ferirá por sua própria mão, e que ele se lhe virá entregar. $4^{a}$ Que ficará senhor da cidade e Império de Constantinopla, de que será coroado por Imperador. $5^{a}$ Que tornará com dois pendões vitoriosos a seu reino. 6" Que introduzirá ao Pontífice e à Fé de Cristo as dez tribos de Israel prodigiosamente aparecidas. $7^{\mathrm{a}}$ Que será instrumento da conversão e paz universal de todo o Mundo, que é o último fim para que Deus o escolheu. ${ }^{21}$

Vieira identifica aqui a conversão mundial como o objetivo último do reino português, o que só poderia ser realizado se retomasse sua soberania. A atuação missionária, juntamente com a restauração portuguesa, seria uma etapa da história de Portugal, que possibilitaria a retomada um projeto que teria sido interrompido com a anexação por Castela. Nas palavras de Vieira:

Quem considerar o reino de Portugal no tempo passado, no presente e no futuro, no passado o verá nascido, no presente ressuscitado e no futuro glorioso; e em todas estas três diferenças de tempos e estados the revelou sempre Deus e mandou interpretar primeiro os favores e as mercês tão notáveis com o que o determinava enobrecer: na primeira, fazendo-o, na segunda, restituindo-o, e na terceira, sublimando-o. ${ }^{22}$

A restauração configura-se assim como uma ressurreição política e imperial, além de evangélica, pois não se poderia fazer as coisas que faltavam sem se ressuscitar seu empreendedor, ou seja, Portugal, representado na figura de D. João IV que, segundo o jesuíta, ressuscitaria para realizar as profecias que the eram destinadas. ${ }^{23}$

\footnotetext{
${ }^{21}$ VIEIRA, 1952. p.36.

${ }^{22}$ VIEIRA, 1992. p.72.

23 VIEIRA, 1952.
} 
Devemos entender a atuação missionária de Vieira inserida no contexto da restauração, que estaria presente não só na questão indígena, mas em toda a problemática da alteridade, procurando estabelecer um lugar para o outro na cosmologia lusitana. No caso do indígena brasileiro, consideraria que, após a conversão, este seria inserindo no corpo místico da Igreja, ${ }^{24}$ sendo identificado como súdito do rei e bom cristão. ${ }^{25}$ No entanto, o índio antes da conversão, não era tido como igual, o que possibilitava uma relação de superioridade. Assim, quando Vieira critica o cativeiro ilícito, está condenando o cativeiro de iguais, por não aceitar a escravidão de índios convertidos (das missões), a menos que se manifestem de plena vontade, pois só após a conversão adquiririam razão e, em conseqüência, teriam vontade própria. ${ }^{26}$

Tal fato é demonstrado em Sermão pregado no Maranhão, onde lembraria aos colonos portugueses a necessidade de não se afastarem de sua missão por achar que o gentio seria bruto, tronco ou pedra, pois haveria a possibilidade, e necessidade, de convertêlos, transformando pedras em homens, ou até mesmo em santos.

Concedo-vos que esse índio bárbaro e rude, seja uma pedra, veja o que faz em uma pedra a arte. Arranca o estatuário uma pedra dessas montanhas, tosca, bruta, dura, informe, e depois que

${ }^{24}$ PÉCORA, 1992b

${ }^{25}$ MAGALHÃES, 1999a.

${ }^{26}$ Vieira classificaria os índios do Maranhão em: os que servem como escravos; os que moram nas aldeias de El-rei como livres e os que vivem no sertão com sua natural liberdade. Ao realizar tal classificação, proporia que os que servissem como escravos, se quisessem permanecer com seus donos, assim o fariam, e os que não, iriam viver nas aldeias de El-rei. Seriam realizadas entradas nos sertões para resgatar aqueles que estivessem para ser comidos em cordas, tornando-se cativos, assim como os escravos tomados em guerra justa. Além disso, propõe que os índios que vivessem nas aldeias de El-rei trabalhassem seis meses por ano para os colonos, recebendo pelo serviço duas varas de pano de algodão. Sermão da Primeira Dominga da Quaresma. Tal proposta seria retomada no Sermão da Epifania, pregado na corte após expulsão dos jesuítas do Maranhão. Sermão da Epifania. 
desbastou o mais grosso, toma o maço e o cinzel na mão, e começa a formar um homem, primeiro membro a membro, e depois feição por feição, até a mais miúda: ondeia-lhes os cabelos, abre-lhe a boca, avulta-lhe as faces, torneia-lhe o pescoço, estende-lhe os braços, espalma-lhe as mãos, divide-lhe os dedos, lança-lhe os vestidos: aqui desprega, ali arruga, acolá recama: e fica um homem perfeito, e talvez um santo, que se pode por no altar. O mesmo será cá, se a vossa indústria não faltar à graça divina. É uma pedra, como dizeis, este índio rude? Pois trabalhai e continuai com ele (que nada se faz sem trabalho e perseverança), aplicai o cinzel um dia e outro dia, daí uma martelada e outra martelada, e vós vereis como dessa pedra tosca e informe fazeis não só um homem, senão um cristão, e pode ser que um santo. ${ }^{27}$

Para Vieira, o direito à salvação seria anterior a todos os outros, sendo possível até, em casos extremos, suprimi-los em favor da salvação da alma. Em contrapartida, o direito primordial dos colonos portugueses seria a evangelização, sendo que este poderia levar a outros, como o dos descimentos, da guerra justa e dos aldeamentos. Assim, se reforça a idéia de que, para Vieira, o outro só teria existência dentro do corpo da Igreja e que, devido à diversidade do homem, muitas vezes seria necessário suprimir alguns direitos secundários para satisfazer o primário, a salvação da alma. Porém, esta não seria a regra, mas sim a exceção. Vieira não deixa de condenar o cativeiro, sendo este considerado um dos maiores males da vida terrena. ${ }^{28}$

${ }^{27}$ Sermão do Espírito Santo, p. 424.

${ }^{28}$ Em sermão onde ressalta a grandeza de São Pedro Nolasco por lutar contra a escravidão de Portugueses pelos mouros, demonstra sua indignação frente a esta prática. "Compreende esta obra suprema de misericórdia os dois maiores males, e os dois maiores bens desta vida e da outra. O maior mal desta vida é o cativeiro, e o maior mal da outra é a condenação; e destes dois males livram os redentores aos cativos, tirando-os de terra de infiéis. O maior bem desta vida, é a liberdade, e o maior bem da outra, é a salvação. E estes dois bens conseguem os mesmos redentores aos cativos, passando-os a terra de cristãos. Pelo bem e mal desta vida, são redentores do corpo: pelo bem e mal da outra vida, são redentores da alma: e por uma e outra redenção, são redentores do homem todo, que se compõe de alma e corpo, como o foi Cristo". Sermão de São Pedro Nolasco, p.366/367. 
Outro aspecto importante que deve ser realçado é a influência que a Companhia de Jesus e a Contra Reforma teriam na obra do Padre Antonio Vieira, pois o Concílio de Trento, ao combater as teses defendidas por Lutero, afirma a universalização da fé católica e a necessidade de sua expansão, sendo missão da igreja levar o evangelho a toda criatura. ${ }^{29}$

O Concílio de Trento justifica a expansão do cristianismo partindo da noção de Lei Natural, ${ }^{30}$ segundo o qual todo homem teria capacidade de saber o que era certo ou errado. Esta noção afetaria diretamente as ações missionárias na América. Segundo Alcir Pécora, ${ }^{31}$ a visão dos protestantes frente ao novo mundo e seus habitantes era a de nostalgia de um tempo perdido onde o homem, devido à sua inocência, não necessitaria ainda da intervenção do Estado em sua vida. ${ }^{32}$ Esses viam o índio como o bom selvagem, porém, impossibilitado de conversão pois, segundo o dogma da predestinação, "o selvagem americano quedaria definitivamente

${ }^{29}$ GREEN, 1984.

${ }^{30}$ Segundo os teóricos do Concílio de Trento, o homem, logo após ser expulso do paraíso, passou a viver em estado de natureza, segundo sua consciência, sem um poder superior para guiá-lo. Esta ausência era no entanto, ilusória, haja visto que, pelo fato de Deus tê-lo dotado de razão, ele seria capaz de identificar por si suas doutrinas. Neste estado natural, não havia a necessidade de persuasão entre os homens, pois cada indivíduo agia por sua consciência. No entanto, por ser ele um ser caído, havia uma tendência para o egoísmo e para a negação do outro, o que o levou a se organizar para formar um Estado de direito que o auxiliasse a seguir corretamente o estado de natureza. Assim, há uma delegação de poderes para uma pessoa que iria governar em nome das outras com o objetivo de garantir o bem comum (SKINNER, 1996). ${ }^{31}$ PÉCORA, 1992a.

${ }^{32}$ Este tempo perdido se configura de modo diferenciado do estado de natureza defendido pelos católicos, pois, diferentemente deste, os protestantes não acreditavam que houvesse uma lei natural que guiasse o homem dotado de razão, mas sim uma ingenuidade que se perde com a expulsão do paraíso, sendo que, devido a esta expulsão, fizera-se necessário a instituição de governos de caráter divino. 
excluído da salvação". ${ }^{33}$ Sua imagem estaria vinculada a idéia de uma época paradisíaca perdida, associado a um pessimismo escatológico.

Entre os jesuítas predominava uma visão diferenciada pois, ao aceitarem que os índios eram dotados de razão, esperava-se sua conversão, o que possibilitaria sua inserção no catolicismo. Não tinham, ao contrário dos protestantes, uma visão do bom selvagem, mas sim a do índio bárbaro, boçal e preguiçoso. Esta imagem aparentemente negativa era associada aos seus maus-costumes, o que poderia ser estirpado com a atuação da Igreja. Não há uma idealização do índio americano, o que não significa que não pudessem estar inseridos em projetos idealizantes. No caso do Padre Antonio Vieira, este fato se torna claro quando entendemos sua teologia vinculada aos ideais messiânicos portugueses. Nas palavras de Alcir Pécora:

Se há idealização, em Vieira, não é diretamente em relação ao índio, mas ao projeto global que se insere: o do avanço decisivo do corpo do exército dos novos conversos, sob o comando da cabeça cristianíssima ao Rei de Portugal, formado no espírito da Igreja militante - vanguarda de instrumentos a afinar os aparentes desconcertos da história com o oculto da providência -, e prestes a gerar o sublime de um império, o quinto e último, que se estende, em mansidão e sossego, milenarmente até quando chegar o juízo final e o eterno bem após dele. ${ }^{34}$

A idéia de um reino universal cristão vinha sendo reafirmado desde o ataque de Lutero ao catolicismo e a formação de Igrejas nacionais. ${ }^{35}$ A Igreja universal teria um caráter supranacional, onde o poder eclesiástico estaria nas mãos da Igreja e o temporal nas mãos do príncipe. Vieira, ao retomar a discussão sobre o Reino Universal Cristão, passa a esperá-lo fora de Roma, centralizado no rei de Portugal, que acumularia tanto a jurisdição temporal quanto espiritual.

33 PÉCORA, 1992a. p.35.

34 PÉCORA, 1992a. p.44.

35 SKINNER, 1996. 
Tal debate teológico, na obra de Vieira, deve ser entendido à luz da situação política de Portugal do século XVII, marcado principalmente pela restauração portuguesa. Coerente com o espírito da Companhia de Jesus, Vieira acreditava que sua atuação política deveria se espelhar na espiritual, estando sempre atento às palavras do evangelho que, por ser escrito de forma que estaria além da compreensão humana, traria sempre as respostas para o bom andamento das coisas mundanas. ${ }^{36}$ Alia assim a idéia de Quinto Império do Mundo à necessidade de consolidação da dinastia de Bragança, entendendo os portugueses como herdeiros de Israel, sendo as profecias bíblicas destinadas também aos portugueses. ${ }^{37}$

Segundo Vieira, muitas destas profecias não teriam sido interpretadas corretamente devido ao fato de, até o momento, não terem ocorrido os fatos necessários para que isto ocorresse e sem as quais seria impossível identificar com precisão de quem e para quem se falava. Além disso, devia-se levar em consideração o fato de que os doutores da igreja, até então, não estavam preocupados em desvendar tais promessas, mas sim em entender os mistérios de Cristo, provando sua reencarnação. ${ }^{38}$

Vieira entendia assim os portugueses como o povo escolhido por Deus para levar a fé para todas as criaturas, possibilitando que Portugal realizasse os desígnios a ele destinado: o estabelecimento de um Império Universal Cristão. Tal perspectiva estava aliada à busca de legitimação e consolidação da restauração portuguesa, que teria sido proclamada por Deus, e assim seria inevitável. ${ }^{39}$ Tal discurso estaria, no entanto, vinculado a um projeto evangelizador amplo pois, para o jesuíta, a idéia de reino teria uma dupla valência, como pátria e como área religiosa, sendo a primeira delimitação da

\footnotetext{
36 PÉCORA, 1996.

${ }^{37}$ SARAIVA, 1992.

38 VIEIRA, 1992.

39 VIEIRA, 1952.
} 
segunda ${ }^{40} \mathrm{e}$, desta forma, uma expansão lusitana levaria necessariamente a uma expansão da fé. ${ }^{41} \mathrm{O}$ reino, por ter sido fundado por Deus,${ }^{42}$ teria como finalidade expandir o cristianismo e levar a fé para todos os povos, estabelecendo seu reino na Terra e garantindo mil anos de felicidade, antes do Juízo Final. ${ }^{43}$

${ }^{40}$ BAÊTA NEVES, 1988.

${ }^{41}$ MAGALHÃES, 1999.

${ }^{42}$ De acordo com a Lenda de Ourique, Deus teria prometido ao futuro rei de Portugal, D. Afonso Henriques, um reino que teria proteção divina. Segundo Vieira, esta teria sido a primeira profecia a respeito do estabeleci-mento de um Império Universal Cristão, liderado pelo rei de Portugal D; João IV (VIEIRA, 1992. p.75).

${ }^{43}$ DELUMEAU, 1997. 


\section{Referências Bibliográficas}

ALVARES, Fernando Jesús Bouza. 1640 perante o Estatuto de Tomar: memória e juízo do Portugal dos Filipes. In: HESPANHA, Antonio Manuel (Dir.). A Restauração e sua época. Lisboa: Cosmos, 1993.

AZEVEDO, João Lucio. História de Antonio Vieira. 2. vol. Lisboa: Clássica, 1992.

BAÊTA NEVES, Luis Felipe. Palavra, Mito e História no Sermão dos Sermões do Padre Antonio Vieira. In: RIEDEL, Dirce Côrtes (Org.). Narrativa, Ficção e História. Rio de Janeiro: Imâgo, 1988.

BOSI, A. Dialética da Colonização. São Paulo: Companhia das Letras, 1992.

BUESCU, Ana Isabel. Sentimento e Esperanças de Portugal. HESPANHA, Antonio Manuel (Dir.). Portugal na época da Restauração. Lisboa: Cosmos, 1993.

CABRAL DE MELLO, Evaldo. O negócio do Brasil: Portugal, os Países Baixos e o Nordeste (1641-1669). Rio de Janeiro: Topbooks, 1998.

CARDIM, Pedro. O Processo Político. In: HESPANHA, Antonio Manuel (Coord.). História de Portugal: O Antigo Regime. Lisboa: Estampa, 1998.

CIDADE, Hernâni. Padre Antônio Vieira. Lisboa: Arcádia, 1947.

COSTA, João Paulo. O Império e os diplomatas da restauração. STVDIA. Lisboa: Instituto de investigação científica tropical. / Centro de estudos históricos e cartografia antiga, n.48, 1989.

DELUMEAU, Jean. Mil anos de felicidade: uma história do paraíso. São Paulo: Companhia das Letras, 1997.

FERREIRA REIS, Arthur Cesar. O Comércio Colonial e as Companhias Privilegiadas. In: HOLANDA, Sérgio Buarque de. História Geral da Civilização Brasileira: A Época Colonial. Tomo I. Rio de Janeiro, Bertrand Brasil, 1993.

FREITAS, Gustavo de. A Companbia Geral do Comércio do Brasil (1649 - 1720). Coleção da Revista de História. São Paulo, 1951. 
GREEN, V.H.H. Renascimento e Reforma Luterana. Lisboa: Dom Quixote, 1984.

GUIMARÃES, Lucia Maria Paschoal. A percepção dos fundadores do Instituto Histórico e Geográfico Brasileiro. In: MARTINS, Ismênia de Lima, MOTTA, Rodrigo Patto Sá \& IOKOI, Zilda Gricoli (Org.). História e Cidadania: coletânea do XIX Simpósio Nacional de Históira - ANPUH. São Paulo: Humanitas, 1998, tomo II.

HESPANHA, Antonio Manuel. As faces de uma Revolução. HESPANHA, Antonio Manuel (Dir.). A Restauração e sua época. Lisboa: Cosmos, 1993.

LISBOA, João Francisco. Vida do Padre Antônio Vieira. São Paulo: W.M.Jackson, 1964.

MAGALHÃES, Joaquim Romero (Org.). História de Portugal: No Alvorecer da Modernidade. Lisboa: Estampa, 1997.

MAGALHÃES, Leandro Henrique. A Legitimidade da Restauração Portuguesa a partir do Discurso do Padre Antonio Vieira. Curitiba: Universidade Federal do Paraná, 2000. (Dissertação, Mestrado em História).

MAGALHÃES, Leandro Henrique. Olhares sobre a Colônia: Vieira e os Índios. Londrina: EDUEL, 1999.

MAGALHÃES, Leandro Henrique. Tensões e Conflitos no I Reinado: A Relação do Eu com o Outro. Boletim do CCH. Londrina: UEL, n.32, 1997.

MAGALHÃES, Leandro Henrique. Vieira e a Economia da Restauração. III Congresso Brasileiro de História Econômica e IV Conferência Internacional de História de Empresas. Curitiba: UFPR, 1999.

MARQUES, A . H. de Oliveira. Breve História de Portugal. Lisboa: Presença, 1995.

MENEZES, Sezinandro Luiz. Padre Antônio Vieira, a cruz e a espada. São Paulo: Universidade de São Paulo, 1992. (Dissertação, Mestrado em História)

ODÁlIA, Nilo (Org.). Varnhagen. São Paulo: Ática, 1974, p.15-21. 
PALACIN, Luis. Vieira e a visão trágica do barroco. São Paulo: HUCITEC, 1986.

PÉCORA, Alcir. O bom e o boçal ou o selvagem americano entre calvinistas franceses e católicos ibéricos. Remate de Males. Campinas, UNICAMP, n.12, p.35-44, 1992.

PÉCORA, Alcir. Política do céu (anti-Maquiavel). In: NOVAES, Adauto (Org.). Ética. São Paulo: Companhia das Letras, 1996. PÉCORA, Alcir. Vieira, o Índio e o corpo místico. In: NOVAES, Adauto (Org.). Tempo e História. São Paulo: Companhia das Letras, 1992.

RIBEIRO, Gladys Sabina. "Pés-de-chumbo" e "Garrafeiros": conflitos e tensões nas ruas do Rio de Janeiro no Primeiro Reinado (18221831). Revista Brasileira de História. São Paulo: ANPUH: Marco Zero, v.12, n.23/24, p.141-165, Set. 91/Ago. 92.

SARAIVA, Antonio José. Antonio Vieira, Menasseh Bem Israel e o Quinto Império. In: História e Utopia: estudos sobre Vieira. Lisboa: Ministério da Educação, 1992.

SERRÃO, Joaquim Veríssimo. História de Portugal: A Restauração e a Monarquia Absoluta (1640-1750). Lisboa: Verbo, 1982.

SERRÃO, Joaquim Veríssimo. História de Portugal: Governo dos Reis Espanhóis. Lisboa: Verbo, 1979.

SKINNER, Quentin. As Fundações do Pensamento Político Moderno. São Paulo: Companhia das Letras, 1996.

TELMO, Antonio. História Secreta de Portugal. Lisboa: Vega, 1977.

VIEIRA, Padre Antonio. Carta ao Padre André Fernandes (Esperanças de Portugal). SĖRGIO, Antonio, CIDADE, Hernâni (Orgs). Obras escolhidas: Vieira Perante a Inquisição. Lisboa: Sá da Costa, 1952, v. VI.

VIEIRA, Padre Antonio. História do Futuro. BUESCU, Maria Leonor Carvalhão (Org.). Lisboa: Casa da Moeda, 1992.

VIEIRA, Padre Antonio. Sermões. Seleção de Padre Gonçalves Alves. Lisboa: Lello, 1951. 


\section{Resumo}

A questão indígena na obra do Padre Antonio Vieira é constantemente abordada, principalmente por estudiosos brasileiros. Apesar de alguns autores levarem em consideração as questões políticas que envolvem a atuação missionária do jesuíta, poucos consideram sua postura frente a restauração portuguesa. O presente artigo tem por objetivo demonstrar, de modo sucinto, como Vieira entendia a questão indígena à luz de suas preocupações com o reino, aliadas às suas expectativas messiânicas.

\section{Abstract}

The indigenous matter in Priest Antônio Vieira's work is constantly approached, mainly for Brazilian specialists. In spite of some authors take account of the political matters that involve the jesuit's missionary performance, a few of them consider his posture over the Portuguese Restoration. The present article has the purpose of demonstrating, in a brief way, how Vieira understood the indigenous matter in the light of his concerns about the new dynasty, allied to his messianic expectations. 